\title{
Anticoagulation effect of extracts of leaves of Ocimum basilicum L. and Ficus palmata $\mathbf{F}$.
}

\section{Johra Khan**}

*Department of Medical Laboratory Sciences, College of Applied Medical Sciences, Majmaah University, Al Majmaah, 11952, Saudi Arabia *Health and Basic Sciences Research Center, Majmaah University, Al Majmaah, 11952, Saudi Arabia

\section{Article Info}

Article history

Received 1 Ocotober 2021

Revised 17 November 2021

Accepted 19 November 2021

Published Online 30 December 2021

\section{Keywords}

Ocimum basilicum $\mathrm{L}$.

Ficus palmata $\mathrm{F}$.

Anticoagulant

Bleeding time

Clotting

Prothrombin time

\begin{abstract}
Ocimum basilicum L. and Ficus palmata F. are two famous plants, found in Saudi Arabia and are part of food and beverages from ancient time. In this study, we evaluated the effect of leaf and fruit extracts of $O$. basilicum and F. palmata on prothrombin time (PT), activated partial thromboplastin time (APTT), and thrombin time (TT). The aqueous, methanol, and ethanol extracts of leaves and fruits were prepared to a concentration of $50 \mathrm{mg} / \mathrm{ml}$. PT and APTT were measured using an automated digital coagulation analyser using normal and poor plasma platelet samples. The plasma samples were tested against different concentrations of both plant extracts as: $0.1,0.5,1.0 \mathrm{mg} / \mathrm{ml}$. The clotting and bleeding time were determined by anticoagulation activity in vitro. The results show that the aqueous leaf extract of $O$. basilicum and $F$. palmata prolongs the APTT, TT, and PTT significantly. The methanol and ethanol extracts of fruits of $F$. palmata produce significant change in PTT, APTT $(p<0.05)$ values but no significant effect on TT values in relation to control. The results show that leaf extracts of $O$. basilicum and $F$. palmata produce significant effect on coagulation activity of human serum, so both species can be potentially drugs targets of naturally derived anticoagulants.
\end{abstract}

\section{Introduction}

Herbs and medicinal plants are part of daily life in Asian and Middle East countries. The use of medicinal plants is considered effective and safe due to their natural occurrence from ancient time (Farouk et al., 2016). Medicinal plants are big source of pharmaceutical drugs around the world and due to their diversity of compounds with minimum side effects (Aly et al., 2014). These phytochemicals contain many bioactive compounds like flavonoids, alkaloids, terpenoids, steroids, phenols, and tannins (Said et al., 2010; Rasool et al., 2017; Awuchi et al., 2021). The herbal medicines prepared from different plants like Allium sativam, Melicope semecarpifolia, and Ocimum sanctum are recorded to exhibit anticlotting activities (Almarshad, 2019; Appiah et al., 2020).

Many Ocimum sp. are also found effective in haemostatic and cardiovascular disease conditions. In countries like India, species of Ocimun are considered holy basil and worshiped (Opalchenova et al., 2003). Similarly, Ficus sp. is also found to be effective against 50 different diseases (Patel et al., 2014). Ficus sp. is also reported beneficial against liver diseases, asthma, gastrointestinal diseases, and many skin diseases. Phytochemical study of dry leaves of Ficus sp. recorded phytosterols, amino acids, hydrocarbons, volatile components, phenolic compounds, fatty acids, and many other metabolites. Some other commonly studied plants are angelic root, devils claw, ginseng, alfalfa, and garlic. In search of new potential

Corresponding author: Dr. Johra Khan

Department of Medical Laboratory Sciences, College of Applied Medical Sciences, Majmaah University, Al Majmaah, 11952, Saudi Arabia

E-mail:j.khan@mu.edu.sa

Tel.: +966538077360

Copyright (c) 2021 Ukaaz Publications. All rights reserved.

Email: ukaaz@yahoo.com; Website: www.ukaazpublications.com drugs which are more powerful, easily affordable, and safe. We conducted this study to evaluate the haemostatic effect of aqueous, methanol, and ethanol extracts of $O$. basilicum and F. palmata.

\section{Materials and Methods}

\subsection{Plant material collection}

The leaves and fruits of $O$. basilicum (Specimen No. Linn749.5) and $F$. palmata (Specimen No. Foss 3418483) were collected from residential area around Majmaah. The botanical identification was conducted by Botany Department of Gauhati University, Assam. Methanol and diethyl ether were supplied by Loba chemicals, India. After collection, the plant parts were dried in shade and grounded to fine powder (Prabhu et al., 2019).

\subsection{Extract preparation}

The aqueous plant extracts were prepared by soaking $10 \mathrm{gm}$ of plant extract powder in $100 \mathrm{ml}$ sterile boiled water for a week at $25^{\circ} \mathrm{C}$ with interim shaking. After one week, the mixture is then centrifuged at $5000 \mathrm{rpm}$ for $5 \mathrm{~min}$ and the supernatant is then evaporated by rotary evaporator. The methanol and ethanol extract of plant species are obtained by dissolving $10 \mathrm{gm}$ of powder in 100 $\mathrm{ml}$ of $70 \%$ methanol and ethanol for 1 week, followed by centrifugation and evaporation of extract.

\subsection{Blood sample collection and preparation}

The selection of volunteers was based on health status with no disease history, no medication, and not doing smoking. The ethical approval for recruitment and blood sample collection is taken from Gauhati University, Assam, India under Number: - 64/29952.The blood samples were collected in citrate tube, and each sample was 
prepared by centrifugation of sample at $3000 \mathrm{rpm}$ for $15 \mathrm{~min}$ to get platelets poor plasma (PPP). Within $2 \mathrm{~h}$ of sample collection the PT, APTT, and TT were analysed.

\subsection{Whole blood bleeding and coagulation time}

Blood coagulation time was assessed by following modified method of Lee and White (Lee and White, 1913). In this method, $1 \mathrm{ml}$ of blood sample was placed in a standard dry test tube at $37^{\circ} \mathrm{C}$ in water bath. The coagulation time of each test tube was measured at each 30 min time interval until the test tube can be inverted without blood spilling. The coagulation time is measured and an average is taken for each test. To record the effect of plant extracts on coagulation time, each plant extract is added in 3 different concentrations of $0.05 \mathrm{ml}$, $0.1 \mathrm{ml}$, and $0.2 \mathrm{ml}$ which is equitant to $(21,42$, and $84 \mathrm{mg} / \mathrm{ml})$ to each blood sample and clotting time is recorded.

To measure the effect of plant extracts on bleeding time, thumb prick blood was absorbed lightly by touching it on filter paper until bleeding stops and no more strain is obtained on filter paper. The effects of extract were measured by adding the plant extract immediately to the pricked thumb blood and time of blood stopping is measured.

\subsection{Measurement of PT, APTT and TT}

The in vitro assay of PT was carried out by incubating $50 \mathrm{ml}$ of PPP with $50 \mathrm{ml}$ of each plant extract for $5 \mathrm{~min}$ at $37^{\circ} \mathrm{C}$. The clotting time was immediately recorded after adding $100 \mathrm{ml}$ PT reagents. The APTT was measured by adding $50 \mathrm{ml}$ of PPP to $50 \mathrm{ml}$ different plant extract and incubated for $2 \mathrm{~min}$ at $37^{\circ} \mathrm{C}$, followed by adding 50 $\mathrm{ml}$ APTT reagent and incubated at $37^{\circ} \mathrm{C}$ for another $3 \mathrm{~min}$. The APTT clotting time was recorded immediately after adding $100 \mathrm{ml}$ of $\mathrm{CaCl}_{2}$ (Calcium chloride). The thrombin time is calculated by Hardisty and Ingram method (Hardisty et al., 1956). $0.05 \mathrm{ml}$ of ethanol, methanol, and aqueous extract of $O$. basilicum and F. palmata was added to $0.1 \mathrm{ml}$ plasma in a normal tube, followed by $0.2 \mathrm{ml}$ of thrombin solution and time of fibrin clot was recorded. The control for all tests was prepared by replacing plant extract with $0.05 \mathrm{ml}$ of normal saline.

\subsection{Statistical analysis}

The data obtained is presented as mean \pm SEM. The statistical analysis of the data was done using Prism software version 8.2 (San Diego, CA, USA). The results of control and plant extract treated groups were analysed using one-way ANOVA and $p<0.05$ was considered significant.

\section{Results}

The result of examined samples were denoting samples have no individual variation $(p<0.01)$ in data for TT, PT, APTT, blood coagulation, and bleeding time. Data of various result shows that leaf extract of both $O$. basilicum and $F$. palmata significantly increases PT, APTT, and TT time.

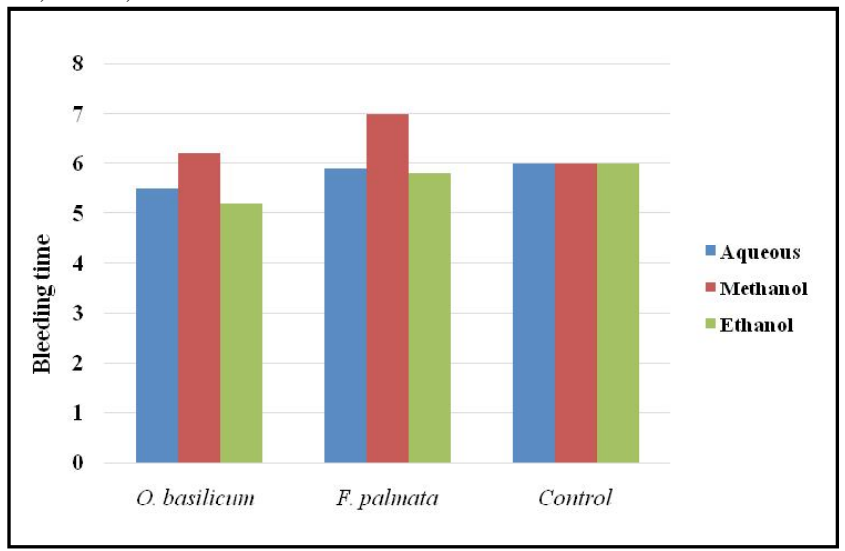

Figure 1: Effect of aqueous, methanol, and ethanol extract on bleeding time in comparison to control which does not have any extract added.

Table 1: PT, APTT, and TT assay (O. basilicum and $F$. palmata) of both plant extracts

\begin{tabular}{|c|c|c|c|c|c|c|c|c|c|c|c|c|c|}
\hline $\begin{array}{l}\text { Plant } \\
\text { species }\end{array}$ & $\begin{array}{l}\text { Type of } \\
\text { extract }\end{array}$ & $\begin{array}{c}\text { PT } \\
(0.05)\end{array}$ & $\begin{array}{l}\text { PT } \\
(0.1)\end{array}$ & $\begin{array}{c}\text { PT } \\
(0.2)\end{array}$ & $\begin{array}{c}p \\
\text { values }\end{array}$ & $\begin{array}{l}\text { APTT } \\
(0.05)\end{array}$ & $\begin{array}{c}\text { APTT } \\
(0.1)\end{array}$ & $\begin{array}{l}\text { APTT } \\
(0.2)\end{array}$ & $\begin{array}{c}p \\
\text { values }\end{array}$ & $\begin{array}{c}\text { TT } \\
(0.05)\end{array}$ & $\begin{array}{c}\text { TT } \\
(0.1)\end{array}$ & $\begin{array}{c}\text { TT } \\
(\mathbf{0 . 2})\end{array}$ & $\begin{array}{c}p \\
\text { values }\end{array}$ \\
\hline \multirow[t]{3}{*}{ O. basilicum } & Aqueous & 170.8 & 168.9 & 171.6 & $0.002 *$ & 356.9 & 362.2 & 345.6 & $0.001 *$ & 11.5 & 10.5 & 11.7 & $0.003 *$ \\
\hline & Methanol & 15.9 & 14.8 & 14.2 & 0.785 & 50.6 & 79.4 & 64.3 & $0.002 *$ & 21.7 & 15.2 & 12.1 & $0.001 *$ \\
\hline & Ethanol & 34 & 32 & 34 & $0.003 *$ & 355.4 & 376.5 & 243.2 & $0.002 *$ & 10.3 & 11.2 & 11.6 & $0.001 *$ \\
\hline \multirow[t]{3}{*}{ F. palmata } & Aqueous & 110.7 & 115.8 & 112.4 & $0.001 *$ & 320.8 & 354.3 & 322.5 & $0.001 *$ & 14.1 & 15.6 & 12.1 & $0.002 *$ \\
\hline & Methanol & 11.9 & 16.5 & 14.4 & 0.889 & 82.4 & 87.2 & 44.2 & 0.445 & 16.4 & 17.5 & 14.3 & $0.001 *$ \\
\hline & Ethanol & 33 & 34 & 24.5 & $0.004 *$ & 129.3 & 112.6 & 234.4 & 0.185 & 12.1 & 11.2 & 10.8 & $0.001 *$ \\
\hline
\end{tabular}

$* p<0.05$ represent level of significance.

\subsection{Thrombin time}

The results of thrombin time of the study showed $0.05 \mathrm{ml}$ and $0.1 \mathrm{ml}$ aqueous extract of both plants $O$. basilicum and $F$. palmata produced very significant decrease in TT time in comparison to control (Table 1).

\subsection{Prothrombin time and activated partial thromboplastin time}

Ethanol and aqueous extract of $O$. basilicum prolong PT and APTT significantly $(p<0.05)$ whereas, the aqueous leaf extract of $F$. palmata very significantly increases PT and APTT values but their was no effect on TT values (Table 1).

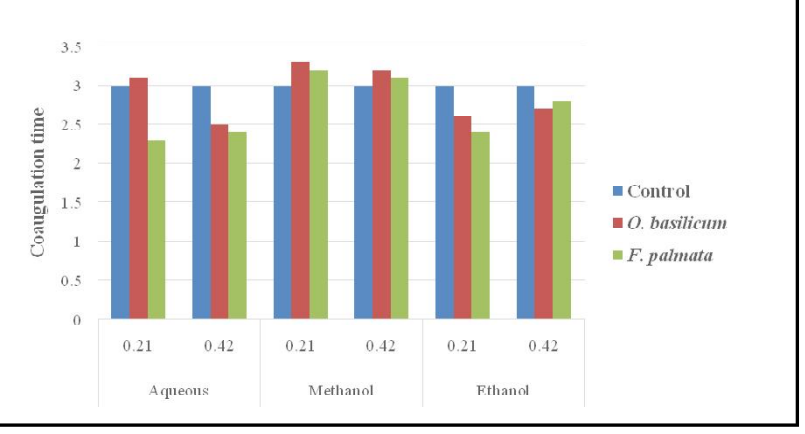

Figure 2: Effect of aqueous, methanol, and ethanol extract on coagulation time in comparison to control. 


\subsection{Blood clotting and bleeding time}

The aqueous and ethanol extract of both the plants in 21 and $42 \mathrm{mg} /$ $\mathrm{ml}$ concentrations produced a significant decrease with a $p$ value of 0.023. Ethanol and aqueous extract of both the plants reduced the bleeding time significantly in comparison to control (Figure 1). The plasma clotting time was measured with different concentrations of $(0.05 \mathrm{ml}, 0.1 \mathrm{ml}$, and $0.2 \mathrm{ml})$ of both plant extracts. The aqueous, methanol and ethanol extract of $O$. basilicum in 21 and $42 \mathrm{mg} / \mathrm{ml}$ reduced plasma clotting time as calculated in minutes (Figure 2).

\section{Discussion}

$O$. basilicum also known as sweet basil is used as an aromatic and medicinal plant and also added to food and beverages for flavour. Similarly, F. palmata is a common fruit known for its lots of medicinal benefits. Many studies are conducted to study different phytochemical structures and medicinal properties of these plants including antimicrobial and antioxidant activities. Due to broad use of these two plant species, we selected them for our study as no similar study was conducted on these two plants.

The analysis of PT, TT, and APTT are important to screen the haemostatic functions of a patient having bleeding related disorders. Even though these are not considered specific tests but a lot of research are conducted in search of drugs which can help in reducing time for PT, TT, APTT, bleeding, and clotting time (Abdallah et al., 2019). The result of our studies indicate reduction in PT and APTT which is very important to fall within the normal ranges as prolonged PT, TT, and APTT can be due to deficiency in one or more than one factors II, V, VIII, IX, X, XI, and XII. Similarly, short PT is found in cancer and hypercoagulable due to which, the surgery becomes difficult. Similar data was recorded with aqueous and ethanol extract of T. spicata and S. thymbra (Emeka, 2021). The methanol extract of both the plants did not produce any significant effect on PT, TT, and APTT $(p<0.05)$. Different studies conducted to find out the effect of extracts of T. spicata, S. thymbra and $V$. fruticulosum also recorded significant increase in PT and APTT values but, the results were not very highly significant (Farouk et al., 2016; Hamid et al., 2020). The normal range of APTT is $34 \mathrm{sec}$, plant extracts of $O$. basilicum and $F$. palmata extract reduced the time $30.4 \pm 0.50$ and $6.9 \pm 0.30 \mathrm{sec}$ in $0.05 \mathrm{ml}$, and $0.1 \mathrm{ml}$ concentration. The aqueous and ethanol extract of F. palmata in 0.1 and $0.2 \mathrm{ml}$ concentration reduce clotting time to a very significant time $(p<0.05)$. Both extracts have great coagulation properties, which is independent of any activating agents.

Since the coagulation process in blood needs production of thrombin and conversion of fibrinogen to fibrin in presence of zymogens, and this occurs on activation of factor X. Single molecule of factor X can generate thousand thrombin molecules, making it a drug target for development of anticoagulation drugs. Different studies conducted of factor X confirms the effects of plant polyphenols on factor $\mathrm{X}$ and the study by Balanescu and his team recorded the presence of flavonoids like quercetin and rutin in $O$. basilicum (Balanescu et al.,2020). Our result confirms the effect of $O$. basilicumflavonoids on factor X and on PT and APTT. Our study of these plants presents them as good candidates for anticoagulation formulation development and drug discovery research.

\section{Conclusion}

In this study, we focused on efficiency of $O$. basilicum and $F$. palmata. The result clearly indicates that the leaf extract of these plants are potential drug candidates to be used to decrease bleeding time and help in coagulation process. This study also supports the synergic effect of bioactivities of different plants as anticoagulants to different degrees of solubility of different molecules. Since various factors like location, environment, period of collection and vegetative cycle can affect the composition further in vivo analysis of purified bioactive compounds is recommended.

\section{Conflict of interest}

The author declares no conflicts of interest relevant to this article.

\section{References}

Almarshad, F. M. (2019). Comparative study of prothrombin complex concentrate and the combination of Spinacia oleracea L. extract with prothrombin complex concentrate on the reversal of apixaban anticoagulation in a rabbit model. Ann. Phytomed., 8(1):116-118.

Ba-Hamdan, A.H.A.; Aly, M. and Bafeel, S. (2014). Antimicrobial activities and phytochemical analysis of the essential oil of Ocimum basilicum, collected from Jeddah Region, Saudi Arabia. J. Microb. R., 4(6): 1-9.

Badgujar, S.B.; Patel, V.V.; Bandivdekar, A.H. and Mahajan, R.T. (2014). Traditional uses, phytochemistry and pharmacology of Ficus carica: A review. Pharmac. Bio., 52(11):1487-1503.

Balanescu, F.; Mihaila, F.D. I.; Cârâc, G., Furdui, B.; Vinãtoru, C.; Avramescu, S. M.; Lisa, E.L.; Cudalbeanu, M. and Dinica, R. D. (2020). Flavonoid profiles of two new approved Romanian Ocimum hybrids. Mol., 19(20):45-73.

Egbuna, C.; Awuchi, C.G.; Kushwaha, G.; Rudrapal,M.; Patrick-Iwuanyanwu, K.C.; Singh, O.; Odoh, U.E.; Khan, J.; Jeevanandam, J. and Kumarasamy, S. (2021). Bioactive compounds effective against type 2 diabetes mellitus: A systematic review. Cur. Top. Med. Chem., 21(12):1067-1095.

Emeka, P.M. (2021). In vitro studies of Bryophyllum pinnatum crude extract on blood coagulation indices: An investigation on its traditional medicine use. Pharma. Res., 13(4):268-273.

Farouk, A.; Fikry, R. and Mohsen, M. (2016). Chemical composition and antioxidant activity of Ocimum basilicum L. essential oil cultivated in Madinah Monawara, Saudi Arabia and its comparison to the Egyptian chemotype. J. Ess. Oil Bear. Pla., 19(5):1119-1128.

Hamid, T.N.; Sharma, R.; Thakur, A.; Kumar, P.and Gautam, S. (2020). Phytochemical extraction and quantification from wild pomegranate flavedo powder, their antioxidant and antimicrobial properties. Ann. of Phytomed., 9(1):187-194.

Hardisty, R.M.; Ingram, G.I.C. and Stacey, R.S. (1956). Reserpine and human platelet 5-hydroxytryptamine. Exper., 12(11):424-425.

Lee, R.I. and White P.D. (1913). A clinical study of the coagulation time of blood. Am. J. Med. Sci., 145:496-503.

Omar, G.; Abdallah, L.; Barakat, A.; Othman, R. and Bourinee, H. (2019). In vitro haemostatic efficacy of aqueous, methanol and ethanol plant extracts of three medicinal plant species in Palestine. Braz. J. of Bio., 80:763-768.

Opalchenova, G. and Obreshkova, D. (2003). Comparative studies on the activity of basil: An essential oil from Ocimum basilicum L.against multidrug resistant clinical isolates of the genera Staphylococcus, Enterococcus and Pseudomonas by using different test methods. J. of microb. meth., 54(1):105-110. 
Ossei, P.; Appiah-Kubi, A.; Ankobea-Kokroe, F.; Owusu-Asubonteng, G.; Ayibor; W.; Aninkora, O.; Taylor, J.; Fenteng, E.; Agyemang-Duah, E. and Agagli, B. (2020). The culture of herbal preparations among pregnant women: A Remedy or a Suicide Potion: A case report and mini review. Case rep. in path., 2020, 1-6.

Rex, B.; Prabhu, S. and Kumar, J.S. (2019). Antifungal efficacies of plant extracts against Alternaria solani (Ellis and Martin) jones and grout under in vitro condition. Ann. Phytomed., 8(1):1-5.
Said-Al Ahl, H. and Mahmoud, A.A. (2010). Effect of zinc and/or iron foliar application on growth and essential oil of sweet basil (Ocimum basilicum L.) under salt stress. Oz. J. of App. Sc., 3(1):97-111.

Singh, D.; Singh, B. and Goel, R.K. (2011). Traditional uses, phytochemistry and pharmacology of Ficus religiosa: A review. J. of Ethnopharm., 134(3):565-583.

Sultan, P., Rasool, S. and Hassan, Q.P. (2017). Picrorhiza kurroa Royle ex Benth. A plant of diverse pharmacological potential. Ann. Phytomed., 6(1):63-67.

Johra Khan (2021). Anticoagulation effect of extracts of leaves of Ocimum basilicum L. and Ficus palmata F. Ann. Phytomed., 10(2):298-301. http://dx.doi.org/10.21276/ap.2021.10.2.40 